\title{
APROXIMACION AL ESTUDIO DE LOS MUNICIPIOS NO CAPITALES DE PROVINCIA, SUPERIORES A 100.000 HABITANTES
}

\author{
$\mathbf{P} \bigcirc \mathbf{R}$ \\ Jose María Serrano Martínez \\ Departamento de Geografía General \\ Universidad de Murcia
}

\section{INTRODUCCIÓN}

Aunque la mayor parte de las civilizaciones han tenido un sustrato urbano esencial, el peso y la importancia de éste nunca ha sido tan grande como ahora $^{1}$. De la misma forma que se observa anualmente un incremento de la población mundial, se constata que la concentrada en las ciudades alcanza de año en año un porcentaje aún mayor ${ }^{2}$. Sin ninguna duda estamos ante un predominio urbano en las formas de vida que se manifiesta en múltiples detalles, a veces tan asumidos que casi no se percatan. Los modelos urbanos se presentan como formas ideales que of recen a la población la posibilidad de alcanzar un conjunto mayor de satisfaciones y de esperanzas tenidas como importantes ${ }^{3}$. Esta tendencia, con diversas matizaciones, puede verse en países con sistemas de desarrollo diversos, incluso contrapuestos 4 .

Si bien el ritmo del incremento de la población urbana es distinto entre las naciones y áreas de la Tierra también ello se debe, en buena medida, a que se parte de una situación enormemente diferenciada fruto de una evolución económica y social divergente durante mucho tiempo.

1 Es interesante la sintesis que hace JonEs, E.: Pueblos y ciudades. Buenos Aires, 1973. Ed. Eudeba, 166 páginas. También la obra de MuNFord, L.: Perspectivas urbanas. Buenos Aires, 1969. Ed. Emecé, págs. 160-216.

2 Al respecto, son acertadas las palabras que escribe FERRER REGALES, M.: El proceso de superpoblación urbana. Madrid, 1972. Ed. Confederación Española de Cajas de Ahorros, págs. 47-90. Nos parece adecuada también la exposición de Mongàn, E.: La ciudad en crisis. Barcelona, 1979. Ed. Pomaire, págs. 181-268.

3 Cfr.: LABORIT, H.: El hombre y la ciudad. Barcelona, 1973. Ed. Kairós, págs. 159-203.

4 El éxodo rural hacia la ciudad se observa tanto en los países desarrollados de economía liberal, caso de España, como en los subdesarrollados. En este sentido se pronuncia SANTOS Miltón, refiriéndose a América latina: Geografía y economía urbana en los paises subdesarrollados. Barcelona, 1973. Ed. Oikós-Tau, págs. 24161. En las naciones de economía planificada el crecimiento urbano se mueve desde luego, en otros niveles; la iniciativa privada casi desaparece; a pesar de esto las ciudades crecen a mayor ritmo de lo que suelen preveer los organismos de planificación. Ello produce una fuerte eseasez de viviendas y de otros servicios urbanos; un caso concreto de esta situación se halla en Hungría: FODOR, L.; SCHULTZ, J.: Budapest. París, 1972. La documentation francaise. Notes et études documentaires, págs. 48-51. PALOS, M.: Hongrie 81. Budapest, 1982. Ed. Corvina Kiadó, págs. 231-6. 
España no ha sido una excepción a todo esto. Fue sobre todo a partir del siglo pasado cuando se inició el crecimiento acelerado de la población: Lo mismo se empieza a producir en la concentrada en las ciudades. Los datos globales que señalan estos valores son bien indicativos. Mientras que en 1900 el total de la población urbana era de cerca de 6 millones de habitantes sobre un conjunto de más de 18,5 , en 1950 ascendía a más de 14,5 milloṇes sobre un censo superior a los 28 millones. En los últimos decenios la cifra no ha dejado de crecer: en 1960 superaba ya los 17 millones sobre 30; en el 70 eran 20 millones de 34 y en el 80; 24 millones de los 37,5 del censo ${ }^{5}$.

La proporción alcanzada por el conjunto de la población urbana sobre el total ha ido en aumento. Ello es fruto de unir al incremento vegetativo natural de las ciudades una fuerte corriente inmigratoria que ha abandonado los medios rurales y se ha dirigido preferentemente hacia las grandes ciudades ${ }^{6}$.

La importancia creciente que alcanzan las ciudades desde el punto de vista demográfico se proyecta igualmente a otros ámbitos de la vida económica y social, con un reforzamiento progresivo del protagonismo económico y funcional de aquellas, frente a los medios rurales. Estos, cada vez, se encuentran más despoblados hasta extremos en que puede ser difícil su futura recuperación; desde luego, se dificulta así un adecuado aprovechamiento económico de todas sus riquezas naturales?

\section{Hipótesis DE TRABAJO Y FUENTES EMPLEADAS}

Dentro del panorama general que se ha esbozado el tema de nuestra atención se limitará a estudiar la evolución seguida por aquellos municipios, que sin ser capitales de provincia, alcanzan en la actualidad (Censo de 1-III1981) una población superior a 100:000.

Para trazar la división entre municipios rurales y urbanos se acude a criterios numéricos de tamaño demográfico junto a otros combinados en que entra la estructura de su población activa ${ }^{8}$; se ha preferido utilizar sólo datos referentes a los primeros, es decir el tamaño demográfico, pero elevando esta cifra, quizás simbólica e incluso artificial, como exponente de aquellos municipios que indiscutiblemente con esa cantidad de habitantes son ya grandes ciudades?.

5 Pueden consultarse los datos exactos hasta 1966 en la obra antes citada de FERRER REgales, M., págs. 173-82. A partir de esa fecha se han obtenido con cálculos sobre los datos del I.N.E., censos correspondientes.

6 Un estudio en que se contempla en su globalidad es: La emigración interior de España de HiguERAS Arnal, A., Madrid, 1967. Ed. Mundo del Trabajo, 129 págs. Referida al decenio 1960-70 cfr.: EsTEBÁNEZ Alvarez, J.; Puyol Antolín, P: "Los movimientos migratorios españoles durante el decenio 1961-70". Rev. Geográphica, 2. época, 1973, págs. 116-122.

Un trabajo monográfico en que se analizan las relaciones ciudad-campo se debe a: VILA VALENTI, J.; CAPEL SAEZ, H.: Campo y ciudad en la Geografía Española. Madrid, Barcelona, 1970. Ed. Salvat, Col. Rtv. 192 págs.

7 Cfr.: Higueras arnal, A., Op. cit. págs. 95-98.

9 A lo largo del texto se emplea indistintamente los términos ciudades y municipios, ambos hacen referencia, aunque impropiamente, al mismo concepto. Sería más correcto hablar siempre de municipios, ya que los totales de población que se citan corresponden al conjunto de la que habita en su término municipal, mientras que por ciudad habría que entender el casco urbano principal. Sin embargo, es algo corriente hacer este uso simultáneo de ambos términos, quizás para salir de la monotonía terminológica; también es más expresivo el segundo que el primero. No hay que olvidar tampoco que la estadística oficial, raramente desciende del nivel municipal. 
Dada la tradicional división territorial española vigente desde 1833 , los municipios capitales de provincia han contado con un apoyo muy fuerte por parte de los poderes públicos para conseguir y mantener un constante crecimiento, acelerado en lo que va de $\operatorname{siglo}^{10}$. Con frecuencia el aumento de población en tales ciudades se ha hecho a costa de gran número de municipios de entre los que se sitúan en su espacio administrativo. De esta forma resalta dentro del panorama urbano nacional el importante incremento sufrido por ellas; sólo se ve empañado, en unos pocos, casos con un estancamiento relativo". El apoyo al que antes nos referíamos a venido unido a su calidad de "capitalidad". Ello significaba un constante incremento en su equipamiento funcional terciario que acababa traduciéndose, a través de un efecto multiplicador, en la generación de numerosos puestos de empleo derivados que, en definitiva, servían para atraer a la población inmigrante o, por lo menos, a impedir la salida de personas en aquellos espacios más deprimidos ${ }^{12}$. En su conjunto, estas ciudades deben mucho, en su situación presente, al modelo de organización centralizado existente todavia.

Es útil resaltar que en el título de este artículo se especifica la cualidad de "municipios no capitales de provinvia", evidentemente el motivo de atención son aquellas ciudades que a pesar del centralismo administrativo, al que antes se ha aludido, han logrado un aumento demográfico importante. En 1981 era 17 sobre las 50 existentes en total en España. Si bien cada una puede se fruto de ciertas causas concretas de diversa índole, todas ellas son consecuencia de un desarrollo económico que ha hecho posible alcanzar semejante volumen demográfico. La actividad industrial se presenta como elemento unificador en casi todas, aunque esta adopte formas, circunstancias e intensidades muy variables en cada una ${ }^{13}$.

En relación con las fuentes utilizadas cabe citar que se han tenido en cuenta los datos de los Censos de Población de España de 1900, 1950, 1960, 1970 y 1980, junto a ellas, diversas publicaciones estadísticas, otras fuentes de datos y demás publicaciones de carácter científico que se citan correspondientemente en las notas intercaladas a lo largo del texto.

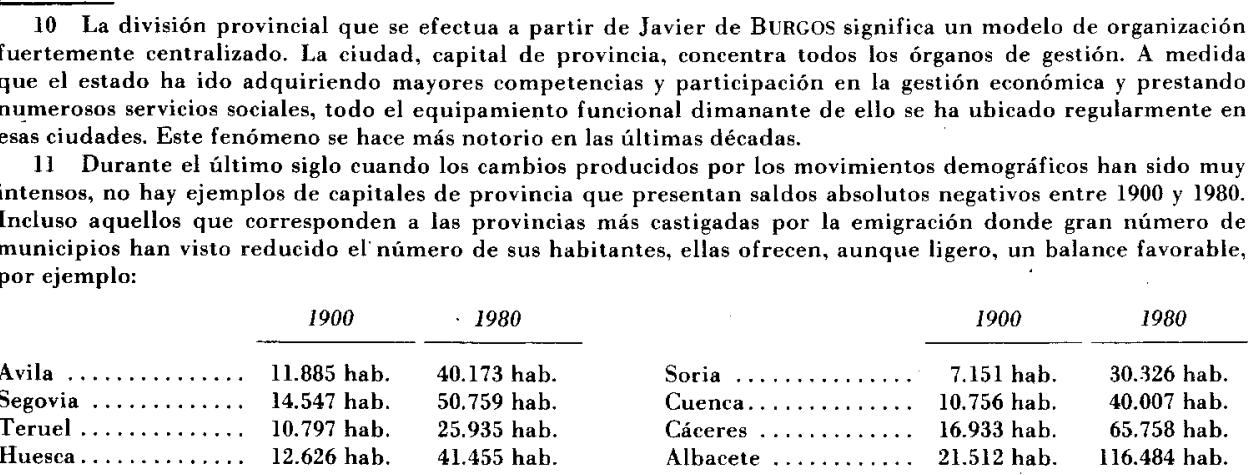

Sin embargo, el cómputo global de la población en esas provincias es en muchos casos negativo o con claros signos de estancamiento.

12 En gran parte de estas provincias "deprimidas" la capital ha sido frecuentemente el único centro capaz de atraer, si bien débilmente, a la población del resto de los municipios.

13 Ciertamente, es la industria el sector que se presenta con una mayor capacidad para generar puestos de trabajo productivos, por lo menos en unos primeros momentos del desarrollo económico. Escribre CAPEL SAEZ, H.: Campo y ciudad... Op. cit. págs. 125-146: "La ind ust ria es un hecho urbano". 


\section{InCREMENTO DE POBlación. DURANTe ESTE siglo}

La evolución que han mantenido durante todo el período de tiempo transcurrido ha sido espectacular. En el primer censo analizado, 1900, no había ninguna ciudad que sin contar con el "status" de capital de provincia superase la cifra señalada de 100.000 habitantes. Desde luego, una de ellas, Cartagena, se aproximaba mucho, ya que contaba con 99.871 h.; el resto estaba a gran distancia, ya que la segunda en tamaño demográfico, Jerez de la Frontera, sólo contabilizaba 63.473 hab.; como se recoge en la Tabla I los resultados de este censo indican que en toda España sólo había seis muncipios (capitales de provincia) que sobrepasaban ese número ${ }^{14}$.

En el segundo censo que se toma como referencia, cincuenta años más tarde, aparecen ya cuatro municipios con más de 100.000 habitantes, son: Gijón, Jerez de la Frontera, Cartagena y Vigo. El incremento demográfico había sido muy fuerte en ellos, no sólo en datos absolutos, también relativos (con base 100 en 1900, en 1950 se llegaba a 233, 169, 113 y 592 respectivamente); resalta la ciudad de Vigo por el mayor aumento conseguido. También puede verse en la Tabla, ya citada, como otros de los municipios, que aún no consigue en esa fecha superar la barrera indicada, muestran ya un ritmo muy fuerte de crecimiento demográfico, caso de Tarrasa, Badalona y La Laguna, todas por encima del 300 por 100 de incremento en esos años.

Separado sólo diez años del anterior censo, en 1960, el total de municipios con una población por encima de la cifra límite usada sube a seis; se han incorporado a los citados: Hospitalet y Sabadell; también en otros dos su población se aproxima: Badalona y Tarrasa; de forma lógica, entre los seis municipios incluidos hay diferencias netas en el ritmo que muestran la evolución de su crecimiento demográfico. Entre todos, el que se sitúa a la cabeza es Vigo, con un total de 144.914 habitantes. En el lado opuesto, los que todavía figuran con un reducido tamaño de población, en ese período censal, son algunos de los madrileños como: Alcorcón, Leganés y Móstoles.

En el censo de 1970 el número de estos asciende a 11. Los incorporados son Elche; Badalona, Santa Colqma de Gramanet, Tarrasa y Baracaldo. El incremento mantenido por ellos desde 1900 , en datos relativos, asciende a: $453 \%, 849 \%, 692 \%$ (en este último caso sólo desde 1950), $858 \%$ y $727 \%$ respectivamente; como demuestran esos valores proporcionales, se trata de un incremento vertiginoso el que vienen soportando. De esta forma los totales absolutos de los principales municipios que se analizan superan los doscientos mil habitantes, Hospitalet se aproxima muy de cerca a esa cifra, Vigo está en torno a los ciento cincuenta mil, etc.

Por último, en el censo de 1980 el número de municipios reseñados asciende a 17 sobre un total de 50 en toda España. Se han incorporado los situados en las proximidades de Madrid: Alcalá de Henares, Alcorcón, Getafe, Leganés y Móstoles; con ello se rompe el especial protagonismo que venían manteniendo las ciudades barcelonesas (más adelante se analizará el reparto espacial de ellas). También el municipio de la La Laguna supera la barrera indicada. El aumento de población en todos ellos sigue un ritmo fuerte,

14 Estas eran: Madrid, Barcelona, Valencia. Sevilla, Málaga y Murcia.

$$
-124-
$$


aunque diferenciado entre sí. Si nos detenemos en este aspecto concreto el incremento porcentual a lo largo del período analizado of rece los siguientes datos:

Cuadro 1

\begin{tabular}{|c|c|c|}
\hline \multicolumn{3}{|c|}{ Incremento de población 1900-1980 (1900 base 100) } \\
\hline 1.2 & Alcorcón $\ldots \ldots \ldots \ldots \ldots \ldots \ldots \ldots \ldots \ldots$ & 21.454 \\
\hline 2.9 & Móstoles $\ldots \ldots \ldots \ldots \ldots \ldots \ldots \ldots \ldots \ldots$ & 11.179 \\
\hline 3.9 & Santa Coloma de Gramanet ............. & 9.312 \\
\hline $4 .^{9}$ & Hospitalet..................... & 5.963 \\
\hline 5.9 & Leganés $\ldots \ldots \ldots \ldots \ldots \ldots \ldots \ldots \ldots \ldots \ldots$ & 3.951 \\
\hline 6.9 & Getafe $\ldots \ldots \ldots \ldots \ldots \ldots \ldots \ldots \ldots \ldots$ & $2: 847$ \\
\hline 7.2 & Alcalá de Henares & 1.224 \\
\hline 8.2 & Badalona......... & 1.194 \\
\hline $9 .{ }^{\circ}$ & $\operatorname{vigo}(\ldots, \ldots, \ldots, \ldots, \ldots, \ldots, \ldots, \ldots$ & 1.123 \\
\hline $10 .{ }^{2}$ & Tarrasa $\ldots \ldots \ldots \ldots \ldots \ldots \ldots \ldots \ldots$ & 975 \\
\hline 11.9 & La Laguna..... . & 811 \\
\hline 12.9 & Sabadell ...... & 799 \\
\hline 13.9 & Baracaldo ...... & 790 \\
\hline $14 .{ }^{9}$ & Elche ....... & 603 \\
\hline 15.9 & Gijón $\ldots \ldots \ldots \ldots \ldots \ldots \ldots \ldots \ldots \ldots \ldots$ & 533 \\
\hline $16 .^{9}$ & Jerez de la Frontera $\ldots \ldots \ldots \ldots \ldots \ldots \ldots$ & 276 \\
\hline 17.8 & Cartagena $\ldots \ldots \ldots \ldots \ldots \ldots \ldots \ldots \ldots$ & 168 \\
\hline
\end{tabular}

Como se observa, aún siendo todos significativos, hay fuertes diferencias. Compárese por ejemplo el incremento de Cartagena, $168 \%$ frente a Alcorcón, $21.454 \%$, sobre 1900. En nueve de estos municipios se supera el incremento del mil por cien; en otros varios se aproxima a esa cifra. El hecho resulta más llamativo si se tiene en cuenta que algunos de ellos sólo aparecen con una población insignificante en el censo de 1900.

Un elemento de comparación que puede emplearse es que mientras el conjunto de la población española, entre 1900 y 1980, sólo ha pasado de base 100 en 1900 a 202 en 1980. Por tanto, de todos ellos, únicamente Cartagena ha tenido un incremento inferior al nacional.

Dentro del panorama urbano español, como ya se ha hecho alguna referencia, el incremento de población de estos municipios se sitúa por encima de los comportamientos medios nacionales, a pesar de la desventaja que subren frente a las capitales provinciales ${ }^{15}$.

Aunque pueda ser arriesgado hacer una previsión de futuro, cabe suponer con cierta seguridad que, aun cuando siga el proceso de crisis de la economía ${ }^{16}$, hay otra serie de municipios que contaban ya en 1980 con una cifra de población cercana a los 100.000 habitantes; sólo con mantener su crecimiento vegetativo, estarán dentro de esta nueva categoría en el próximo $\operatorname{censo}^{17}$.

15 Véase al respecto ló que se dice en el apartad 2. y la nota 9.

16 La crisis general de la economía mundial y sus efectos concretos en España ha producido en los asuntos demográficos algunos efectos que pueden ser coyunturales, pero que están indiscutiblmente ligados a ella. Resaltan en este sentido, los cambios originados en los saldos netos de los movimientos migratorios, especialmente significativos a partir de 1976. Provincias tradicionalmente receptoras de inmigrantes pasan a tener un saldo negativo o estancado, mientras que otras que durante muchos años han servido en especial para nutrir la emigración ahora ofrecen saldos positivos. Pueden confrontarse los datos concretos en el ANUARIO Banesto del Mercado Español, 1983. Madrid, 1984, pág. 308.

17 Estas son: Avilés, 87.996; Cornellá, 91.563; Mataró, 97.008; Algeciras, 85.390; El Ferrol, 87.691; Santiago, 82.404. Mientras que entre los municipios capitales de provincias se encontraban en la misma circunstancia: Gerona, 86.624; Jaén, 95.783 y Orense, 94.346. 


\section{Distribución Espacial de los MUNicipios}

Las figuras 1 y 2 los representan cartográficamente. La primera se limita a ubicarlos en las diferentes provincias mientras que la segunda efectúa una representación proporcional según su diferente tamaño demográfico. Pasamos a comentar esto brevemente. En la actualidad salvo los cinco situados en la provincia de Madrid, los doce restantes se ubican en provincias costeras, e incluso dentro de estas, ocupan posiciones concretas muy próximas al mar cuando no son directamente ciudades portuarias como Vigo, Cartagena, Gijón, etc. Con todo ello se confirma la tendencia demostrada en España de que la población tiende a desplazarse y a alcanzar mayores densidades en la periferia que en el centro ${ }^{18}$.

Una excepción importante a lo anterior sucede con las mencionadas ciudades madrileñas, como se verá más adelante; han surgido como consecuencia de la existencia de dicha metrópolis. Esta desplaza hacia sus alrededores a ciertos grupos de industrias, unidas a otras funciones variadas; para ello se escogen tanto municipios antiguos con tradición histórica, caso de Alcalá de Henares, como otros núcleos de creación casi reciente.

El relativo equilibrio espacial que aparece configurado en 1980 es sólo algo reciente, ya que con anterioridad existía dentro del predominio costero una fuerte concentración de estas ciudades en la provincia de Barcelona. Esto se configura especialmente en la década de 1960.

Fuera de estas dos provincias que contabiliza cada una cinco municipios, los restantes son todos ejemplos únicos y aislados en sus correspondientes demarcaciones provinciales. En ciertos casos son estos municipios los que adquieren un claro protagonismo urbano dentro de su provincia superando ampliamente en volumen demográfico y otros aspectos funcionales que se vinculan a él, a la capital provincial; es el de Vigo-Pontevedra' ${ }^{19}$; más atemperada se presenta la relación entre Gijón-Oviedo y Jerez de la FronteraCádiz ${ }^{20}$. En otros, estos municipios, sin ensombrecer el panorama jerárquico de la red urbana provincial, se sitúan netamente en un claro nivel secundario con una especialidad funcional delimitada frente a la capital correspondiente. Ello sucede en "Cartagena-Murcia y Elche-Alicante ${ }^{21}$. En los restantes, el tamaño demográfico de estos municipios y su correspondiente importancia económica y funcional no significan una dualidad nodal ni una alternativa

18 El desplazamiento de la población desde el centro a la periferia se inicia de forma constante desde el siglo XVII. Cfr.: NADAl, Oller, J.: Historia de la población española. Barcelona, 1963, Ed. Ariel, 223 págs.; VICENS VIVes, J.: Historia Económica de España. Barcelona, 1969, 7. ed., Vicens Vives, págs. 440-59; Anes, G.: El Antiguo Régimen. Los Borbones. Madrid, 1975. Ed. Alfaguara, págs. 7-42.

19 Miralbés Bebera, R.: Galicia en su realidad geográfica. Santiago, 1984. Ed. Fundación Pedro Barrié de la Maza, págs. 353-599, El sistema gallego de asentamientos y el equipamiento funcional terciario, es abordado.

20 La población de Oviedo era en 1981: 184.473 hab. frente a 256.433 de Gijón. Cfr. TERáN ALVAREZ, M. de: "Asturias y Santander". En Geografía Regional de España, vol. II, $2^{\mathrm{a}}$ Ed. 1969. Ed. Ariel, págs. 70-74.

21 La población de Cartagena ascendía a 167.936 hab. y la de Murcia a 284.585. La de Elche a 164.779 hab. y la de Alicante a 245.963. Cfr.: Serrano Martínez, J. M.': La red urbana de Murcia. Murcia, 1983. Ed. Servicio de Publicaciones de la Universidad de Murcia, 71 págs. Serrano Marrínez, J. M. ${ }^{a}$ : Jerarquía de ciudades y áreas de influencia en la Región de Murcia. Ed; Editorial Regional. En prensa; MoRALEs GiL, A.: "La red viaria en el área metropolitana de Alicante-Elche". Rev. Inales de la Universidad de Alicante. Instituto Universitario de Geografía, n. ${ }^{\mathcal{1}}$ 1. 1983, págs. 51-66. 
frente a lo que ofrecen las correspondientes capitales de provincia, casos de Madrid, Barcelona y Bilbao 22 .

En el apartado anterior cuando se hacía referencia a la evolución de estos municipios se decía que a pesar de su incremento demográfico importante y común en todos ellos este mantenía unos ritmos muy distintos entre sí, de ahí las fuertes diferencias absolutas. Como se vé en la figura 2, se observa en conjunto como son las ciudades situadas en torno a Barcelona las que alcanzan un mayor tamaño demográfico, quizás fruto de que su incremento poblacional viene de atrás y la inmigración ha sido más fuerte. Ello se contrapone a lo reciente del incremento sucedido en los municipios madrileños. Hubiera sido casi imposible en tan poco tiempo alcanzar superiores niveles de crecimiento demográfico.

Entre los restantes, resalta por su mayor tamaño los municipios de Gijón y Vigo, ambos por encima del cuarto de millón de habitantes, cifras muy significativas incluso dentro de la jerarquía urbana nacional. Ello se hace más notorio aún frente al tamaño que consiguen los restantes, Baracaldo, Elche, La Laguna y Jerez de la Frontera.

\section{Causas de Su incremento demográfico}

No es sencillo sintetizar en pocas palabras las causas múltiples, complejas y en cada caso singulares que han originado el crecimiento demográfico extraordinario de los 17 municipios analizados. Fácilmente pueden encontrarse razones diferentes detrás de las respectivas ciudades. Desde luego, globalmente, cabe decir que la actividad industrial como hecho "esencialmente urbano" 23 ha sido una razón casi común que frecuentemente aparece en cada uno cuando consigue un desarrollo rápido, si cabe espectacular, como el descrito. Ello no obsta para que otras funciones terciarias también contribuyan al importante crecimiento demográfico municipal24.

En el caso de los municipios que rodean a Barcelona, constituyen en su conjunto un modelo que responde plenamente a ello. La importancia industrial de Cataluña y sobre todo de la provincia de Barcelona y su capital ha sido frecuentemente expuesta como hecho destacado desde el pasado siglo ${ }^{25}$; primero fueron las industrias textiles, lana y algodón, seguidas de la

\footnotetext{
22 En los tres casos, aunque con situaciones muy diferentes, el protagonismo urbano de las correspondientes ciudades, capitales de provincia, es indiscutible frente a los municipios restantes. Su tamaño demográfico, el equipamiento funcional, etc. señalan diferencias acusadas entre sí. Cfr.: TRIAS BERTRAN, C.: La contribución urbana y la distribución de la aglomeración madrileña. Madrid, 1964. Ed. I.E.A.L.; TRIAS FARGAS, R.: Introducción a la economía de Cataluña. Madrid, 1974. Ed. A.E., págs. 122-32; Geografía de Catalunya. Barcelona, 1968, vol. III. Geografía Comarcal 2, págs. 363-686 debido a los autores: LlobET, S.; REBAGLIATO, J.; VILA, P. y CASASSAS, LL. por último para Bilbao y las ciudades vascas el tema ha sido tratado ampliamente por Ferrer Regales, M. y Precedo Ledo, A. J.: "Las ciudades centrales del sistema Vasco-navarro". Rev. Estudios Geográficos, núm. 138, 1975, págs. 325-49.

23 CaPEL SAEZ, H.: Campo y ciudad... Op. cit. págs. 125-46.

24 BEavon, K. S. O.: Geografía de las actividades terciarias. Una reinterpretación de la teoría de los Lugares Centrales. Barcelona, 1981. Ed. Oikós-Tau, págs. 195-217; Precedo Ledo, A. J.: "El proceso de urbanización en España y sus relaciones con la industrialización y la terciarización". Aportación española al XXIII Congreso Geográfico Internacional de Moscú. Julio-agosto, 1976. Madrid, 1976, págs. 457-75. CAPEL SAEZ. H.; TAtJer, M.; Batllori, R.: "La población básica en las ciudades españolas". Rev. Estudios Geográficos, núm. 118, 1970, págs. 29-76; Díz NiCOLÁs, J.: "Especialización funcional en las ciudades españolas". Rev. Ciudad y Territorio. Madrid, n. ${ }^{0}$ 1, 1971, págs. 3-37; DİZ NicolÁs, J.: Especialización funcional y dominación en lo España Urbana. Ed. Guadarrama. Madrid, 1971, págs. 117 y ss.

25 Trias FaRGas, R.: Introducción a la Economía... Up. cit. págs. 102-15.
} 
química, pero recientemente su campo se fue abriendo a otras actividades: metalurgía, mecánicas y un sinfín de funciones derivadas incluidas dentro del genérico nombre de industrias ligeras ${ }^{26}$. Esencialmente es preciso matizar que el crecimiento demográfico de estos municipios se debe a que dada su cercanía con la ciudad de Barcelona, aparte de su propio equipamiento industrial, en ellos habita una buena parte de la población que trabajan en las numerosas industrias que rodean a la ciudad central. Espacialmente constituyen una extensa conurbación donde se engloban no sólo las ciudades analizadas, también otros municipios que sin sobrepasar esa cifra de cien mil habitantes, se aproximan a ella ${ }^{27}$. En conjunto todo ello origina que sea esta región urbana la que totalice un mayor número de municipios con tan elevada población.

En los alrededores de Madrid también se ubican cinco ciudades, incluidas en este análisis. Fuera de que su tamaño demográfico es algo más reducido que el de los anteriores, su incremento poblacional ha sido mucho más reciente. También en estos casos su evolución hay que situarla en estrecha relación con la ciudad de Madrid, razón inicial y báşica que explica su crecimiento acelerado ${ }^{28}$. En los últimos decenios, Madrid se ha configurado como el tercer núcleo industrial del país ${ }^{29}$. La capital político-administrativa, centro financiero y burocrático empezó a desarrollar una industria variada: artes gráficas, metálicas, alimenticias, metalúrgicas, construcción y un amplio número de otras actividades entre las que no faltan las industrias de alta tecnología. Su ubicación a medida que aumentaban en tamaño e importancia, han ido pasando desde el centro de la ciudad a los espacios periféricos, bien en antiguas ciudades, como Alcalá de Henares, o en núcleos de población de reciente creación y acelerado desarrollo, caso de Alcorcón, Leganés, Móstoles. La especulación del suelo que se produce siempre en torno a los núcleos urbanos es un factor que también contribuye a desplazar a la población económicamente menos favorecida hacia las áreas suburbanas que se extienden ampliamente por los alrededores de las grandes ciudades millonarias, como es el caso de Madrid ${ }^{30}$. Hoy, en su conjunto, constituyen la segunda región urbana de España.

Fuera de estas dos áreas, el resto de las ciudades se presentan, ya se dijo antes, como casos aislados. Quizás Baracaldo escapa un poco de ello, al formar junto a Bilbao y otros núcleos del "bajo Nervión, un espacio metropolitano"

26 Ferrer REGiles, M.: Geografía económica y social de España. Madrid, 1966. Fd. Mundo del tralajo págs. 70-75.

27 Entre otros se pueden citar Manresa, 67.007 hab.; Mataró, 97.008; El Prat de Llobregat, 60.419: San Baudilio de Llobregat, 72.926, etc. Todos estos datos son del censo de 1980.

28 Crr.: Gil Crespo, A.: "Concentración y dispersión de la industria en el área de Madrid". Aportación española al XXI Congreso Geográfico Internacional. Madrid, 1968, págs. 275-286. Trits BrkTRí, C.: Area metropolitana de Madrid. 1984. Madrid. Ed. Ministerio de la vivienda, 153 págs. SAYTos Préc1um, J. M.: "Integración e interrelación de los distritos y municipios del área metropolitana madrileña. Rev. Anales de la universidad Complutense. núm. 2. 1982, págs. 239.259. MExDEZ G. DEL V.JlE. R. "Crisis económica y dispersión industrial en la aglomeración de Madrid. Res. Anales de la tiniversidad Complutense, n. ${ }^{9} 3$, 1983, págs. 175-194; Cussa, J. M.: "Traslados de industrias en el área metropolitana de Madrid. Rev. Geographica. Madrid, año XXIV, págs. 131.159.

29 FERRER Regni.es, M.: Geografía económica... Op. cit. págs. 99 y ss.

30 Cfr.: CAPEL SAEZ, H.: Capitalismo y morfologia urbana en España. Barcelona, 1975. Ed. Los Libros de la Frontera, 143 págs. y BERINGı́J, Ch.: Plan de urbanismo y práctica política. Barcelona, 1974. Los Libros de la Frontera, págs. $79-103$. 
en palabras de Precedo ${ }^{31}$. Fueron varias las causas favorables que coincidieron en este espacio geográfico para hacer de él un emporio industrial. Durante muchos años se mantuvo a la cabeza. Recientemente, la crisis económica y otras diversas razones están incidiendo muy fuertemente sobre él de forma negativa ${ }^{32}$. Baracaldo, centro secundario dentro del sistema urbano vasco, ofrece también junto a su importancia industrial una cierta especialización funcional en comercio al por menor ${ }^{33}$.

Gijón, el municipio más poblado de su provincia, ha basado su desarrollo económico, y a la par demográfico, en la existencia de ricas cuencas carboníferas del interior y en sus proximidades, junto al hecho de contar con un buen puerto de refugio, "el mejor de toda la España Cantábrica"34. Esta situación favorable se vio premiada con la instalación de industrias siderúrgicas, de construcción naval, metálicas, vidrio, químicas y otras ligeras ${ }^{35}$.

El municipio de Vigo, también el más importante económica y demográficamente de su provincia, inicia su despegue económico en los primeros decenios de este siglo. La existencia de un importante puerto pesquero y comercial ha sido factor esencial en su desarrollo. La fuerte actividad industrial que hoy existe, es reciente, se debe a industrias mecánicás, construcción de automóviles, construcción naval, industrias metalúrgicas, conserveras, más una amplia gama de actividades secundarias derivadas de las anteriores $^{36}$.

Como ya se vio, Cartagena, ha sido de todos los municipios estudiados el que menor incremento demográfico proporcional ha mantenido durante los ochenta años analizados. Inicia el siglo siendo un populoso municipio, donde se unía su actividad portuaria, militar, con la existencia de una explotación minera notable en sus alrededores. A partir de los años cuarenta comienza un resurgir ${ }^{37}$ basado en las fuertes inversiones que el Estado realizaba a través

31 Precedo Ledo, A. J.: Bilbao y el bajo Nervión, un espacio metropolitano. Bilbao, 1977. Publicaciones de la Junta de Cultura de Vizcaya, 198 págs.

32 Es interesante constatar que en los últimos años, 1977, 1978, 1979 y 1980, la provincia de Bilbao presenta un saldo migratorio negativo junto con Guipúzcoa después de continuos años en que se ha producido una fuerte corriente inmigratoria hacia ella. Végse ANUARIO BANESTO DEL MERCADo EsPañoL... Op. cit. pág. 308.

33 Precedo Ledo, A. J.: Bilbao y el bajo Nervión... Op. cit. págs. 152-3.

34 Ferrer Regales, M.: Geografía económica... Op. cit. pág. 87.

35 Un estudio temprano se debe a GaRcía PRADo, J.: La villa de Gijón. Estudio de Geografía Urbana. Gijón, 1954. La significación de esta ciudad dentro del sistema urbano asturiano se analiza por MoRALES MAtos, G.: "Organización del sistema urbano asturiano". Rev. Ería. Revista geográfica, n. ${ }^{\circ}$ 3, 1982. Universidad de Oviedo, págs. 55-78.

36 Cfr.: Ropríguez Arzua, J.: El puerto de Vigo. Estudio económico 1900-1975. Vigo, 1981. Ed. Caja de Ahorros Municipal de Vigo, 181 págs. más láminas. También: Precedo LeDo, A. J.: “Algunas consideraciones teórico-conceptuales a propósito del sistema gallego de asentamientos". Homenaje a A. Floristán. Madrid, 1981, págg. 297-318. Precedo LEDo, A. J.: Galicia: “Red urbana y desarrollo regional". Rev. Boletín de la Real Sociedad Geográfica. T.CX, n. ${ }^{\circledR} 1$ al 12. Enero-diciembre, 1974, págs. 161-219. MAaTiNEZ-SARANDESES, J. y GómEZ Mendoza, J.: "El proceso de concentración urbana en Galicia" (1960-70). Rev. Ciudad y territorio. 1975. Enerojunio, págs. 15-26. SÁNCHEZ PÉREZ, E.: "La construcción naval en el N.O. español. Situación y desarrollo". Rev. I.C.E., 1963, n. ${ }^{\circ}$ II. Ministerio de Comercio, págs. 123-32. En ese mismo número de revista hay otros artículos dedicados también a Galicia.

37 Cfr. los trabajos de Bosque Maurel, J.: "Cartagena, notas de Geografía urbana". Rev. Estudios Geográficos, 1940. Madrid, n. 2 37, págs. 579-638. VERLaQue, Ch.: "Carthagene, les elements d'une renaissance". Rev. Annales de Geographie. n. ${ }^{\circ} 405$, 1965, pág8. 560-90. ANDRÉs SARASA, J. L. Cartagena. Crecimiento demográfico y desarrollo industrial. Murcia, 1982. Ed. Universidad y otros organismos, 343 págs. ANDRtes Sarasa, J. L.: Cartagena Estudio de Geografía Urbana. Murcia, 1981. Servicio de Publicaciones de la Universidad de Murcia, 36 páge. Calvo García-Tornel, F.: "El puerto de Cartagena, su evolución reciente". Rev. Anales de la universidad de Murcia, 1980, vol. XXXVII, núms. 1-2, págs. 195-237. 
del I.N.I.; la construcción naval, industrias metalúrgicas y químicas junto con la función comercial (crudos) y militar, son sus soportes esenciales. Pero aparte de lo anterior, no ha sido posible generar actividades derivadas, industrias medianas o pequeñas, que son, en définitiva, la que completan el desarrollo económico y se traducen en un incremento demográfico paralelo ${ }^{38}$.

En Jerez dé la Frontera el crecimiento demográfico también ha sido proporcionalmente de los más reducidos (del índice 100 en 1900 ha pasado a 276 en 1980). A principios del siglo era ya una populosa ciudad que sobresalía dentro de su espacio geográfico. Importante centro agrícola y comercial de los vinos que llevan su nombre, ha conocido en los últimos años un cierto resurgir industrial en sectores derivados de sus riquezas agraria. Pero esta actividad industrial nunca ha alcanzado un peso muy relevante ${ }^{39}$.

Entre los numerosos municipios que han desarrollado una actividad industrial y un crecimiento económico considerable en la provincia de Alicante destaca por su importancia absoluta Elche, su incremento continuo y progresivo se sustenta sobre todo a causa de su capacidad industrial de tipo ligera, entre las que sobresale por su mayr volumen el calzado junto a otras numerosas especialidades. Por lo general, son industrias medianas y pequeñas que precisan de una mano de obra numerosas, lo cual ha servido para incrementar el movimiento inmigratorio ${ }^{40}$.

Por último, La Laguna se presenta como un fenómeno atípico dentro de este panorama; ha sido la función universitaria la que sin duda ha servido en especial para mantener el crecimiento demográfico que continuamente y sin grandes sobresaltos, va desde principios de este siglo al momento presente ${ }^{41}$.

Con todo ello, y como se apuntó con anterioridad, todo núcleo urbano cuando alcanza unas dimensiones de población importantes, aunque deba su origen prioritariamente a una actividad esencial, siempre genera otras funciones derivadas que, con el paso del tiempo, alcanzan a ser también de gran significación ${ }^{42}$. Es lo que se llama el proceso de terciarización. Este llega a ocupar una población laboral numerosa, capaz por sí sola de contribuir al crecimiento urbano. Así, si nos detenemos en el estudio de ciertos parámetros indicativos de la importancia del sector terciario en estos municipios, aunque no sean proporcionalmente tan importantes como en las capitales de provicia, sí consiguen tener unos valores altos ${ }^{43}$.

38 Alvarez Llano, R.: "La inversión industrial durante los años de crisis". Rev. Situación Banco de Bilbao, 1982, n. 1, págs. 45-49. Como es bien conocido, son las industrias pequeñas y medianas las que originan un saldo más positivo en la creación de puestos de trabajo, dada la menor inversión por persona que precisan.

39 Cfr.: Esteve Guenrero, M.: Jerez de la Frontera. Jerez, 1953 y Bosque Maurel, J.: "Andalucía", en Geografía Regional de España... Op. cit. págs. 421-2.

40 Gozalvez Perez, V.: La ciudad de Elche. Estudio Geográfico. Valencia, 1976. Ed. Departamento de Geografía de la Universidad de Valencia, 290 págs. más láminas. En especial interesa para este tema las págs. 145-248. También Ramos Folques, A.: La industria, el comercio y la agricultura en Elche. Elche, 1973. Ed. Lepanto, 306 págs. Gomara Dallo, J.: Estudio demográfico de la industria de Elche. Alicante, 1959. Ed. Instituto de Estudios Alicantinos, 142 págs.

41 Pérez González, R.: La Laguna. Notas de Geografía Urbana. Oviedo, 1971. Instituto Juan Sebastián Elcano. Puldoo Mañas, T.: "Las áreas metropolitanas de Canarias y sus rasgos de diferenciación. Rev. Anuario del Departamento de Geografía de La Laguna, 1981, págs. 190-197.

42 Véase: García Ballesteros, A.; Redondo González, A. y Troitiño Vinuesa, A. M.: "Las actividades terciarias en las ciudades españolas de más de 100.000 habitantes". Aportación española al XXIII Congreso geográfico Internacional de Moscú... Op. cit. 263-79. Con carácter general: TAUVERó, A.: “Le tertiaire superieur moteur du developpement regional?". Rev. L'Espace Géographique, n. ${ }^{9}$ 3, 1974, págs. 169-78.

43 Por ejemplo, entre otros aspectos cabe destacar las licencias fiscales comerciales con que cuentan estos municipios. Véase al respecto el resumen que anualmente publica Banesto en los Anuarios del Mercado Español. Op. cit. 1983, págs. 313-405. 


\section{CONCLUSIONES}

1 En los últimos decenios se observa en España un incremento importante de la población que radica en grandes ciudades. Nuestra atención se dedica a los municipios, no capitales de provincia, superiores a 100.000 habitantes; cifra simbólica que, en cierta medida, representa la mayoría de edad de una ciudad.

\section{TABLA I}

Evolución demográfica de los municipios no capitales de provincia que en 1980 alcanzan los 100.000 habitantes.

\begin{tabular}{|c|c|c|c|c|c|c|}
\hline Provincia & Municipio & 1900 & 1950 & 1960 & 197.0 & 1980 \\
\hline Alicante & Elche.$\ldots \ldots \ldots \ldots \ldots$ & 23.308 & 55.877 & 73.320 & 123.716 & 164.779 \\
\hline Barcelona & Badalona ........... & 19.240 & 61.654 & 92.257 & 163.374 & 229.780 \\
\hline Barcelona & Hospitalet .......... & 4.948 & 71.580 & 122.813 & 240.630 & 295.074 \\
\hline \multirow[t]{2}{*}{ Barcelona } & $\begin{array}{c}\text { Sabadell ............. } \\
\text { Santa Coloma }\end{array}$ & 23.294 & 59.494 & 105.152 & 158.311 & 186.123 \\
\hline & de Gramanet ........ & 1.510 & 15.281 & 32.590 & 105.880 & 140.613 \\
\hline Barcelona & Tarrasa $\ldots \ldots \ldots \ldots$ & 15.956 & 58.880 & 92.234 & 136.952 & 155.614 \\
\hline Cádiz & Jerez de la Frontera.... & 63.473 & 107.770 & 130.900 & 149.337 & 175.653 \\
\hline Madrid & Alcalá de Henares...... & 11.206 & 19.415 & 25.123 & 57.354 & 137.169 \\
\hline Madrid & Alcorcón ............ & 657 & 759 & 3.356 & 46.073 & 140.957 \\
\hline Madrid & Getafe .............. & 4.444 & 12.254 & 21.895 & 69.396 & 126.558 \\
\hline Madrid & Leganés ............ & 4.148 & 5.860 & 8.539 & 56.279 & 163.910 \\
\hline Madrid & Móstoles $\ldots \ldots \ldots \ldots \ldots$ & 1.344 & 2.082 & 2.886 & 17.895 & 150.259 \\
\hline Murcia & Cartagena ............ & 99.871 & 113.160 & 123.630 & 143.466 & 167.936 \\
\hline Oviedo & Gijón .............. & 47.544 & 55.877 & 73.320 & 123.716 & 164.779 \\
\hline $\begin{array}{l}\text { Pontevedra } \\
\text { Santa Cruz }\end{array}$ & Vigo $\ldots \ldots \ldots \ldots \ldots$ & 23.259 & 137.873 & 144.914 & 198.815 & 261.331 \\
\hline de Tenerife & La Laguna $\ldots \ldots \ldots \ldots$ & 13.074 & 41.731 & 57.344 & 77.704 & 106.146 \\
\hline Vizcaya & Baracaldo ........... & 15.013 & 42.240 & 77.802 & 109.185 & 118.615 \\
\hline \multicolumn{7}{|c|}{ Total municipios superiores a 100.000 ha- } \\
\hline \multicolumn{2}{|c|}{ bitantes, no capitales de provincia. } & 0 & 4 & 6 & 11 & 17 \\
\hline \multicolumn{2}{|l|}{ Total España } & 6 & 24 & 26 & 36 & 50 \\
\hline
\end{tabular}

Fuente: Censos de población de España, 1900, 1981.

2 A pesar de las dificultades comparativas que han encontrado estos para su desarrollo, en relación con las capitales de provincia, dada la peculiar estructura administrativa del Estado, el número de los que superan esta cifra va aumentando a mayor ritmo del que lo hacen el conjunto de esas ciudades.

3 El grado de incremento de su población es muy diferente entre unos $y$ otros lo que ha llevado a fuertes disparidades absolutas entre ellos. 
4 Su distribución espacial responde básicamente a dos modelos:

a) Los que se desarrollan amparándose en una ciudad mayor centro de un área industrial de importancia nacional, caso de los cinco situados alrededor de Barcelona, cinco en torno a Madrid y uno próximo a Bilbao.

b) Aquellos que crecen autónomamente y por tanto se ubican separadamente en otras provincias españolas, configurándose como auténticos centros dinámicos alternativos, a veces, las respectivas capitales provinciales donde pertenecen.

5 La actividad industrial, con peculiaridades diferentes en cada caso, se presenta como la razón básica que explica este fuerte incremento de la población. Junto a ella, por supuesto, es posible encontrar otras razones concretas que motivan y originan ese aumento de su población. 


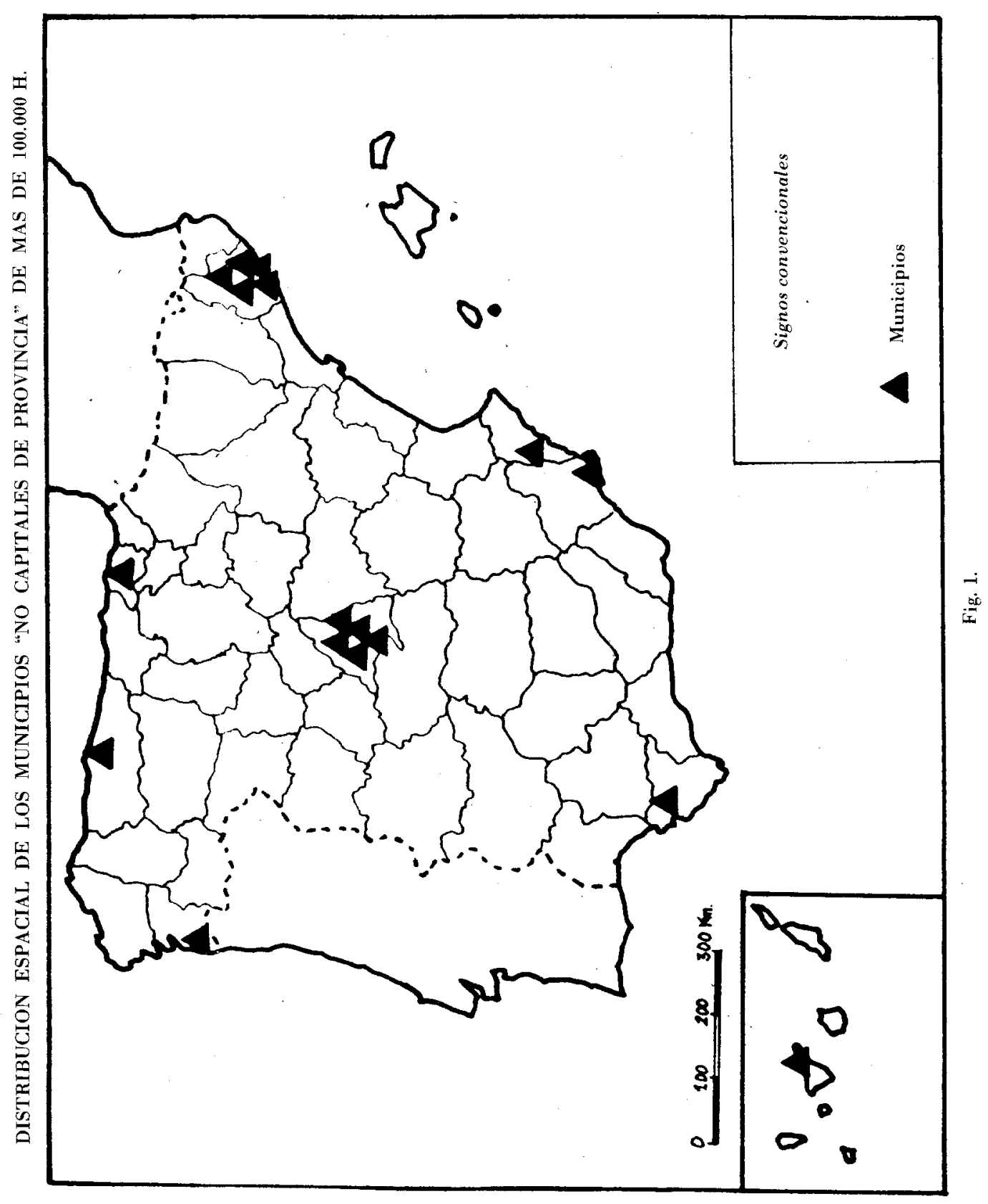




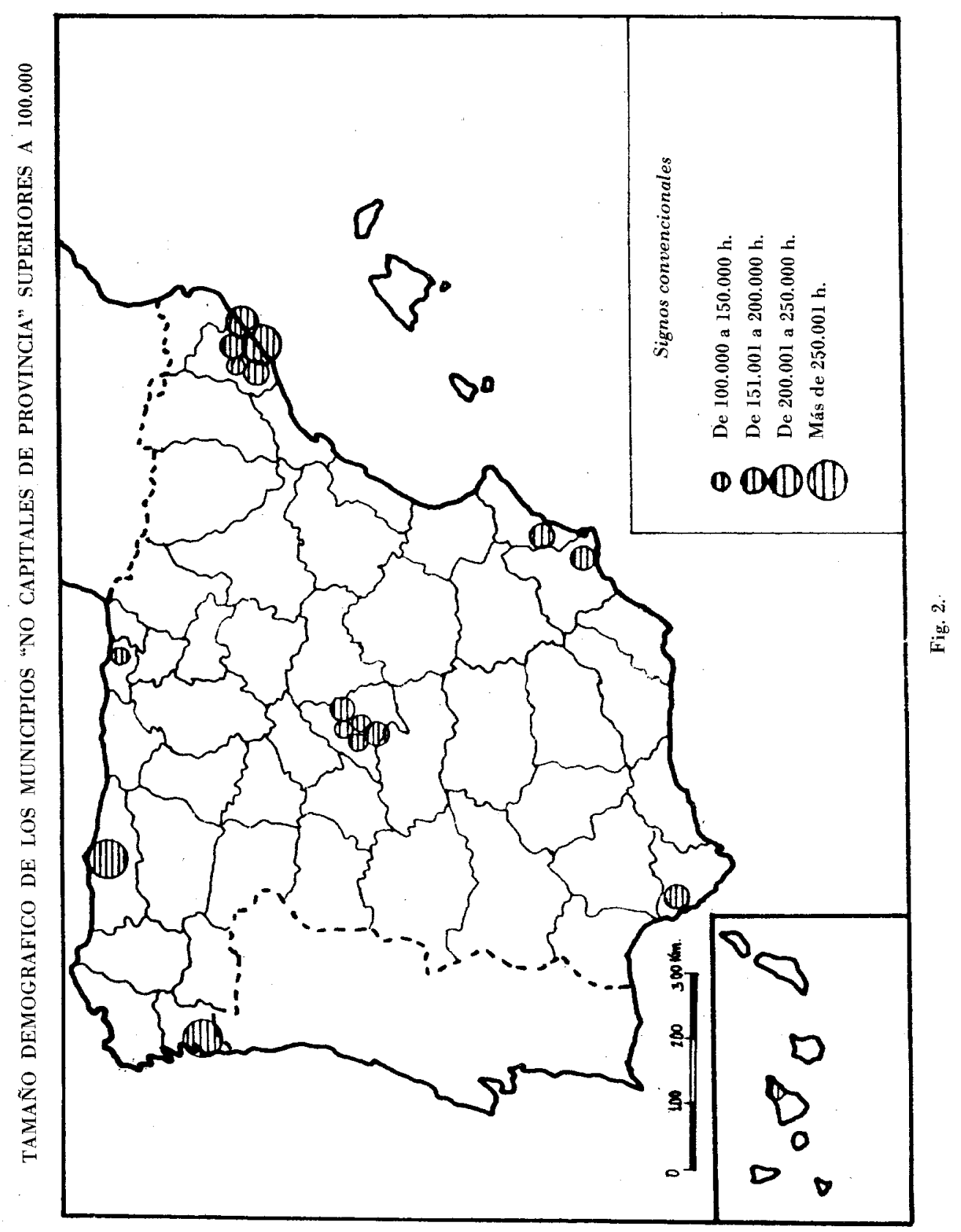

